$\xi=$

\title{
Mediating Role of Fashion Consciousness on Cosmopolitanism and Status Consumption of Young Fashion Consumers in Sri Lanka
}

\author{
Jayarathne $^{1 *}$ \\ ${ }^{I}$ Department of Marketing Management, University of Sri Jayewardenepura, Sri Lanka \\ *Corresponding author E-mail: amilaj@sjp.ac.lk
}

\begin{abstract}
The aim of this paper is to examine the mediating role of fashion consciousness on cosmopolitanism and status consumption of young fashion consumers in Sri Lanka. A survey method is used. The result uncovers that the fashion consciousness fully mediates the relationship between cosmopolitanism and status consumption of young fashion consumers in Sri Lanka. Finally, the paper provides important implications and suggestions for practitioners as well as for academics in the field of consumer behavior.
\end{abstract}

Keywords: Cosmopolitanism, Fashion Consciousness, Status Consumption.

\section{Introduction}

In considering the significance of status consumption behaviour, it was implied that cosmopolitanism and consequently fashion consciousness have brought significant changes in consumers' status consumption. Jin and Kang ${ }^{1}$ claim that Chinese consumers were influenced by Western values and had moved away from a collectivist orientation and consequently their concern on products might also be changed.

More specifically the youth market offers an important target market for fashion and apparel marketers ${ }^{2}$ Further, several studies related to fashion have been carried out in the developed countries, though comparatively very few studies has been done regarding fashion consciousness of consumers in developing countries. ${ }^{3}$ However, the attitudes, beliefs and perceptions of fashion consumers in developed countries are different in a significant manner from those in developing countries. ${ }^{4}$ Owing to cultural uniqueness and influence of Western values ${ }^{4,5}$,Sri Lanka provides a suitable platform for investigating the cosmopolitanism and fashion consciousness on status consumption of young generation in the fashion industry representing the context of developing countries.

In summary, addressing the knowledge gap of comprehensively investigating the influence of cosmopolitanism and fashion consciousness on status consumption in fashion industry as well as contributing the new knowledge based on the context of developing countries, the purpose of the current scrutiny is to examine the mediating impact of fashion consciousness on cosmopolitanism and status consumption of the young fashion consumers in Sri Lanka.

\section{Theory Base in Summary}

O'Cass and McEwen ${ }^{6}$ define Status Consumption (STC) as the behavioral tendency to value one status and acquire products that can provide status and reputation to the individually al. ${ }^{7}$ state that fashion products with higher status has become one of the necessities in consumers' daily life.

Nam et al. ${ }^{8}$ define Fashion Consciousness (FC) as "a person's degree of involvement with the styles or fashion of clothing'. An individual does not have to be either a fashion opinion leader or a fashion innovator to be considered fashion conscious. Cosmopolitanism (COS) refers to a perspective that considers that all individuals are citizens of the world..$^{9} \operatorname{COS}$ can also be defined as adopting cultures, values, and lifestyle from other countries without abandoning one's own cultural values. Thus, COS embedded with global and local values. ${ }^{10}$ Beck $^{11}$ defines COS as internal globalization, globalization from within the national societies' importantly shapes the consumption in the global arena through influencing consumer attitudes and values. ${ }^{9,12,13}$ Cleveland et al. ${ }^{14}$ disclosed that demographic variables including ethnic groups had a significant impact on COS.

Literature discloses that $\mathrm{FC}$ as an important dimension of a person's lifestyle which also affects purchase decision and consumption behavior ${ }^{15}$. Craik $^{16}$ explains that women used fashion to capture and maintain the interest of men and to achieve social status. According to Easey ${ }^{17}$ individuals try to improve his or her selfesteem and social acceptance through the right choice of clothing. Scholars have paid the attention on exploring the association and/or influence of COS and/or FC. Riegels18highlights that fashion is more appropriately linked to COS than to nationalism. This is further proven by Beck ${ }^{11}$ stating that COS enables fashion designers to use their awareness of cultural heritage for creative inspiration, enabling openness towards others and the negotiation of contradictory cultural experiences.

As implied in some existing studies COS, FC and STC are interconnected. Consumers believe that buying and consuming new and better products and brands, and luxury products that are newly available in the market helps them to gain and to enhance their social status.19Accordingly, these consumers are expected to engage more in the acquisition, purchase and consumption of statusenhancing goods and services. The study of Khareet $\mathrm{al}^{20}$ shows 
that global value and culture influence consumers' lifestyle with their choice of fashion products. These fashion products are known to have close association with self-identify and consumer lifestyle.

However, it is worth noting that above literature implied that COS and FC influence STC while COS influence FC too. It highlights the not yet comprehensively answered question of "what the role of FC on the relationship is between COS and STC?' Addressing this gap in the literature the objective of the current paper is to examine the mediating role of fashion consciousness on the influence of cosmopolitanism on consumer status consumption in the fashion industry. Supporting the above discussed literature the following hypothesis is derived

H1: Fashion consciousness mediates the influence of cosmopolitanism on consumer status consumption in the fashion industry.

\section{Methodology}

This is an explanatory study. Population is young consumers of fashion related products (clothing, accessories, and footwear) in Sri Lanka. A sample of 458 undergraduate and postgraduate university students in National Universities in Sri Lanaka were selected reflecting judgmental sampling techniques. Scales of ${ }^{8,21,22}$ are used for measuring COS, FC, and STC respectively. Structural Equation Modeling (SEM) is used with MMOS $^{23}$.

Measurement Model Analysis

Confirmatory Factor Analysis (CFA) was assessed for COS, FC, STC in order to ensure the unidimensional. Then, validity and reliability of the scales were ensured. The results are summarized in Table.

Measurement model ensures the convergent validity and interitem consistency (Table 1). Discriminant validity was assessed using the procedure has been suggested by Fornell and Larcker ${ }^{25}$ Table 2.

Structural Model Analysis

After underlying assumptions for SEM were checked and proved ${ }^{23}$ two models were tested.

Table 1: Summary of the Measurement Modle Statistics

\begin{tabular}{|c|c|c|c|c|}
\hline Construct & $\begin{array}{c}\text { AVE } \\
(>0.7) \\
{[23]} \\
\end{array}$ & $\begin{array}{c}\text { CR } \\
(>0.7) \\
{[23]}\end{array}$ & $\begin{array}{c}\text { Cronbach's Alpha }(\alpha) \\
(>0.7)[24]\end{array}$ & $\begin{array}{c}\text { Factor } \\
\text { Loading } \\
{[23]}\end{array}$ \\
\hline FC & 0.635 & 0.802 & 0.810 & $0.75-0.82$ \\
\hline $\mathrm{COS}$ & 0.752 & 0.810 & 0.880 & $0.79-0.90$ \\
\hline STU & 0.654 & 0.801 & 0.809 & $0.71-0.84$ \\
\hline
\end{tabular}

Notes: Fit indices $\mathrm{X}^{2}(458)=456.43,(\mathrm{p}<0.01), \mathrm{CFI}=0.97, \mathrm{GFI}=0.91$,

$\mathrm{NFI}=0.91, \mathrm{TLI}=0.97, \mathrm{RMSEA}=0.032, \mathrm{SRMR}=0.05 ;$ AVE, average variance extracted; $\mathrm{CR}$, composite reliability; $\mathrm{X}^{2}$, Chi-square; $\mathrm{CFI}$, comparative fit index; GFI, goodness-of-fit index; NFI, normed fit index; TLI, Tucker-Lewis index; RMSEA, root mean square error of approximation; SRMR, standardized root mean residual.

Table 2: Descriptive and Bivariate Correlation Matrix for the Study Constructs

\begin{tabular}{|ll|l|l|l|l|l|}
\hline \multicolumn{2}{|c|}{ Construct } & Mean & SD & $\mathbf{1}$ & $\mathbf{2}$ & $\mathbf{3}$ \\
\hline 1. & FC & 3.94 & 0.67 & $\mathbf{0 . 7 9 6}$ & & \\
\hline 2. & COS & 3.95 & 0.58 & $0.035^{* *}$ & $\mathbf{0 . 8 6 7}$ & \\
\hline 3. & STC & 3.04 & 0.81 & $0.071^{*}$ & $0.014^{* *}$ & $\mathbf{0 . 7 5 7}$ \\
\hline
\end{tabular}

Notes: ** Correlation is significant at $\mathrm{p}<0.01 ; *$ Correlation is significant at $\mathrm{p}<0.05$; $\mathrm{SD}$, standard deviation; Diagonal value in bold-face type indicates the square root of the AVE of individual construct.

\subsection{Model 1 (Mediation Model)}

In Model 1, COS, FC, ST Care the latent variables. The direct effect of COS on STC, and the indirect effect of COS on STC through FC were examined in Model 1. The goodness-of-fit indices for the Model 1 were met: X2 $/ \mathrm{df}=1.709$, GFI $=0.912$, RMSEA $=0.03, \mathrm{NFI}=0.92, \mathrm{CFI}=0.926, \mathrm{TLI}=0.912, \mathrm{AGFI}=$ 0.876 , and PNFI $=0.76$. Overall, the fit indices provided evidence of a reasonably good model fit.
The results of the SEM for Model 1 are displayed in Table 3. Accordingly, COS has positive but not significant impact on STC of the young generation in Sri Lanka $(\beta=0.17, p=0.225)$. COS has a significant positive impact on the $\mathrm{FC}$ of the young generation in Sri Lanka $(\beta=0.24, \mathrm{p}<0.01)$. FC has positive and statistically significant impact on the STC of the young generation in Sri Lanka $(\beta=0.518, \mathrm{p}<0.001)$.

Table 3: Sem Results For Model 1 (Full Mediation)

\begin{tabular}{|l|l|}
\hline Hypothesized path & Standardized path estimates \\
\hline $\mathrm{COS} \rightarrow \mathrm{STC}$ & 0.17 \\
\hline $\mathrm{COS} \rightarrow \mathrm{FC}$ & $0.24 * * *$ \\
\hline FC $\rightarrow$ STC & $0.518 * * *$ \\
\hline
\end{tabular}

Note: $* * \mathrm{p}<0.01$; *** $\mathrm{p}<0.001$; FC, fashion consciousness; COS, Cosmopolitanism; STC, status consumption.

\subsection{Model 2 (Direct Effect Model)}

The Model 2 analyzes the direct impact of COS on STC, however the mediating variable FC is excluded. The Model 2 yields acceptable fit to the data: $\mathrm{X} 2 / \mathrm{df}=1.55, \mathrm{GFI}=0.927$, RMSEA $=$ $0.051, \mathrm{NFI}=0.918, \mathrm{CFI}=0.912, \mathrm{TLI}=0.945, \mathrm{AGFI}=0.896$, and PNFI $=0.69[23]$. COS has significant positive direct impact on STC $(\beta=0.254, p<0.05)$. The collective results of Model 1 and Model 2 assist to test the hypothesis and discloses that FC significantly fully mediates the relationship between COS and STC of the young fashion consumers in Sri Lanka at $95 \%$ confidence level.

\section{Discussion and Conclusion}

This paper is aimed at investigating the mediating role of $\mathrm{FC}$ on COS and STC of young fashion consumers in Sri Lanka. Utilizing the direct and indirect models mediating role of the $\mathrm{FC}$ has been examined. The former model reflects that COS of the young generation in Sri Lanka significantly influence their STC. This finding enriches the existing knowledge on how openness to global cultural values would leads for STC of the community. It is worth noting that scholars who investigate such relationship ${ }^{1,20}$ do specifically examine neither COS nor STC. This study can be considered at the foremost investigation of influence of COS on STC done in the developing countries context taking Sri Lanka as a proxy.

The study discloses that FC fully mediates the influence made by COS on STC of the young generation in Sri Lanka. It reflects that even though Sri Lankan young generation would be more open to accept the Western/global cultural values, but the extent of its influence on their STC depends upon their extent of FC. Empirical and comprehensive investigation of mediating role of $\mathrm{FC}$ on the relationship between COS and the STC of the young generation is a paramount contribution to the existing knowledge around not only fashion orientation but also culture and consumption patterns as none of the previous studies have explicitly investigate such mediating relationship.

Findings of the study imply that COS influences the FC and then FC influence the STC even such two relationships have been taken separately. It enriches the findings of studies of 5 and20though such study did not specifically address the knowledge contributed by this study. Steenkamp et al., ${ }^{19}$ disclose that consumers influenced by cosmopolitanism, buying and consume new products and brands, to gain and to enhance their social status. Fashionable clothing is seen as a symbol that indicate status and therefore a significantly large number of consumers are willing to pay higher prices for fashionable goods with the "benefits" of status and prestige. ${ }^{16}$ It is empirically been confirmed by this study. This study not only adds new knowledge to the fashion industry but also addresses the lack of research in the developing countries. It is because; this study is the first published empirical study that reflects on the mediating impact of fashion consciousness on the 
relationship between cosmopolitanism and status consumption done in the developing countries taking Sri Lanka as a proxy.

Findings provide valuable insights for companies, especially for fashion retailers who target Asian consumers in developing countries, to successfully design and maintain their competitive strategies. Such insights might be mostly similar in other Asian countries and/or in other developing countries, explicitly finding, it is an avenue for future research though.

\section{References}

[1] Jin B \& Kang JH (2011), "Purchase intention of Chinese consumers toward a US apparel brand: a test of a composite behavior intention model", Journal of Consumer Marketing 28(3), 187 - 199.

[2] WY, J \& Li (2011), "How Does FastFashion Influence the Consumer Shopping Behavior of Generation $\mathrm{Y}$ in Hong Kong. The Hong Kong Polytechnic University".

[3] Rathnayaka CP (2011), "An empirical investigation of fashion consciousness of young fashion Consumers in Sri Lanka"YoungConsumers, 12(2), 121-132.

[4] Dickson MA, Lennon SJ, Montalto CP, Shen D \& Zhang L (2004), "Chinese consumermarket segments for foreign apparel products", The Journal of Consumer Marketing 21(5), 301-17.

[5] Jayarathne PGSA \& Warnakulasooriya BNF (2016), "Cosmopolitanism Orientation and Fashion Consciousness of Educated Young Consumers of Fashion Related Products in Sri Lanka, Vidyodaya Journal of Management 2(1),1-22.

[6] A. O'Cass \& McEwen H (2004), "Exploring Consumer Status and Conspicuous Consumption”, Journal of Consumer Behaviour 4(1), 25-39.

[7] Li G \& Kambele Z (2012), "Luxury Fashion brand consumers in China: Perceived value, fashion lifestyle, and willingness to pay", International Business Research 65,1516-1522.

[8] Nam J, Hamlin R, Gam HJ, Kang JH, Kim J, Kumphai P, Starr C \& Richards L (2006), "The fashion-conscious behaviours of mature female consumers", International Journal of Consumer Studies 31(1), 102-110

[9] Cannon H \& Yaprak A (2002), "Will the Real-World Citizen Please Stand Up! The Many Faces of Cosmopolitan Consumer Behavior". Journal of International Marketing 10(4), 30-52.

[10] Yoon SJ, Cannon MH \& Yaprak A (1996), "Evaluating the CYMIC Cosmopolitanism Scale on Korean Consumers", Advance in International Marketing, 7, 211-232.

[11] Bennie F, Murray V \& Gazibara I (2010), "The Global Fashion Industry - Growth in Emerging Markets", [online] /www.forumforthefuture.org/. Available at: https://www.forumforthefuture.org/sites/default/files/project/downl oads/fashionfutures2025finalsml.pdf [Accessed 9 Aug. 2016].

[12] Cleveland M, Erdogan S, Arikan G \& Poyraz T (2011), "Cosmopolitanism, individual-levelvalues and cultural-level values: a cross-cultural study", Journal of Business Research 64(9), 934-943.

[13] Thompson CJ \& Tambyah SK (1999), "Trying to be cosmopolitan" Journal of Consumer Research 26, 214-41.

[14] Cleveland M, Laroche M \& Hallab R (2013), "Globalization, culture, religion, and values: comparing consumption patterns of Lebanese Muslims and Christians", Journal of Business Research 66(8), 958-967.

[15] Sprotles G \& Kendall EA (1986), "Methodology for Profiling Consumers' Decision-Making Styles", Journal of Consumer Affairs 20(2), 267-279.

[16] Craik J, "Fashion: The Key Concepts"Bloomsbury Academic, London.

[17] Easey M, "Fashion Marketing (3rd Ed), Wiley-Blackwell.

[18] Riegels M (2011), "Cat-walking the Nation Challenges and Possibilities in the Case of the Danish Fashion Industry", Journal of Current Cultural Research 3(1), 55-70.

[19] Steenkamp JBEM, Hofstede F \& Wedel M (1999), “A crossnational investigation into the individual and national cultural antecedents of consumer innovativeness", Journal of Marketing 63(2), 55-69.

[20] Khare A, Mishra A, Parveen C \& Srivastava R (2011), "Influence of consumers' susceptibility to interpersonal influence, collective self-esteem and age on fashion clothing involvement: a study on Indian consumers", Journal of Targeting, Measurement and Analy sis for Marketing 19 (3/4),227-242.
[21] Jeffres LW, Atkin DJ, Bracken CC \& Neuendorf KA (2004), "Cosmopoliteness in the Internet Age. Journal of ComputerMediated Communication

10: doi:10.1111/j.10836101.2004.tb00227.x.

[22] Eastman JK, Glodsmith KE \& Flynn LR (2015), "Status Consumption in Consumer Behaviour: Scale Development and Validation", Journal of Marketing Theory and Practice 7(3), 41-52.

[23] Hair JF \& Anderson RE (2010), "Multivariate data analysis" (7th ed.). New Jersey: Prentice Hall

[24] Nunnally JC (1978), "Psychometric theory". New York: McGrawHill.

[25] Fornell C \& Larcker DF (1981), Structural equation models with unobservable variables and measurement error-algebra and statistics. Journal of Marketing Research 18(3), 382-388. 